Tropical Journal of Pharmaceutical Research October 2021; 20 (10): 2077-2082

ISSN: $1596-5996$ (print); 1596-9827 (electronic) (C) Pharmacotherapy Group, Faculty of Pharmacy, University of Benin, Benin City, 300001 Nigeria.

\title{
Studies on the effect of Celastrus orbiculatus (Celastraceae) extract on chemosensitivity of liver cancer cells via Wnt/ $\beta$-catenin pathway
}

\author{
Xiaobo Ding ${ }^{1}$, Laijun Song ${ }^{2}$, Yunfei Lu ${ }^{1}$, Qiting Huang ${ }^{3}$, Chengming Jiao ${ }^{4}$ \\ ${ }^{1}$ Jiangyin Hepatobiliary Hospital of Traditional Chinese Medicine, ${ }^{2}$ Department of Clinical Laboratory, ${ }^{3}$ Department of \\ Hepatobiliary, ${ }^{4}$ Department of Administration, Jiangyin Hepatobiliary Hospital of Traditional Chinese Medicine, Jiangyin 214404, \\ Jiangsu Province, China
}

*For correspondence: Email: jexa1e@163.com; Tel: +86-051086581366

Sent for review: 1 May 2021

Revised accepted: 20 September 2021

\begin{abstract}
Purpose: To examine the efficacy of Celastrus orbiculatus extract (COE) on the chemosensitivity of liver cancer (LC) cells and its mechanism of action.

Methods: Hep G2/ADM cells in the logarithmic growth phase were assigned to a control group (no treatment for cell culture medium only) and a study group $(120 \mu \mathrm{g} / \mathrm{ml} \mathrm{COE}$ added to the culture medium). After $48 h$ of incubation, the biological responses were compared. The study group was divided into groups $A$ and $B$, while control group was divided into groups $C$ and $D$, with $1 \mu$ mol/L XAV939 added in groups $A$ and $C$. Cell proliferation, cell invasion, cell apoptosis rate, and apoptosis protein in the four groups were evaluated.

Results: The study group showed significantly lower values in terms of cell proliferation and cell invasiveness $(p<0.05)$ and a higher apoptotic rate than the control group $(p<0.05))$. The study group also demonstrated an elevated pro-apoptotic protein Bax level and a declined anti-apoptotic protein BCl2 level. In contrast to group B, the proliferation and invasiveness of Hep G2/ADM cells in group A treated with the inhibitor, XAV939, were significantly lower $(p<0.05)$, while the apoptotic rate exhibited a significant increase $(p<0.05)$. There was a rise in the level of pro-apoptotic protein, Bax, and a fall in the anti-apoptotic protein Bcl-2 level in group A. Lower levels of $\beta$-catenin, $c-M y c$, and cyclin D1 protein were observed in the study group compared with the control group $(p<0.05)$. Compared with other groups, the multiplication capacity and invasiveness of cells in group A treated with COE and inhibitor XAV939 significantly declined, while the apoptotic rate increased $(p<0.05)$.

Conclusion: COE reverses drug resistance in chemotherapy by inhibiting the expression of $W n t / \beta$ catenin pathway in $L C$ cells. Therefore, COE has potentials for use along with chemotherapeutic agents in the management of liver cancer.
\end{abstract}

Keywords: Celastrus orbiculatus, Liver cancer, Chemosensitivity, Chemotherapy, Apoptosis, Cell invasion

This is an Open Access article that uses a funding model which does not charge readers or their institutions for access and distributed under the terms of the Creative Commons Attribution License (http://creativecommons.org/licenses/by/4.0) and the Budapest Open Access Initiative (http://www.budapestopenaccessinitiative.org/read), which permit unrestricted use, distribution, and reproduction in any medium, provided the original work is properly credited.

Tropical Journal of Pharmaceutical Research is indexed by Science Citation Index (SciSearch), Scopus, International Pharmaceutical Abstract, Chemical Abstracts, Embase, Index Copernicus, EBSCO, African Index Medicus, JournalSeek, Journal Citation Reports/Science Edition, Directory of Open Access Journals (DOAJ), African Journal Online, Bioline International, Open-J-Gate and Pharmacy Abstracts

\section{INTRODUCTION}

Globally, liver cancer (LC) is the most common pervasive malignant tumor [1], which ranks fifth among malignant tumors in the United States. Although the etiology of LC is still elusive, previous research has pointed out several major causes of LC, including chronic alcohol misuse, 
hepatitis B or hepatitis $C$ virus infection, and food pollution [2].

Nonetheless, few studies have examined the trends in the occurrence of LC triggered by specific causes. The incidence of LC increased from 471,000 cases in 1990 to $1,007,800$ cases in 2016 worldwide, with an increase of $114.0 \%$ [3], which is considered a major global public health issue. Notwithstanding the rapid development of detection technology, the disease may have progressed to an advanced stage at time of diagnosis in most cases, resulting in a poor prognosis [4]. Hepatocellular carcinoma (HCC) accounts for over $90 \%$ of LC cases, for which resection is one of the main treatment methods [5]. A prior study has revealed that the postoperative recurrence of tumors has remained one of the pressing clinical issues to be addressed; hence, systemic chemotherapy has captured great attention in clinical practice [6]. However, the sensitivity of chemotherapy has been severely impaired owing to drug resistance and related issues, which hinders the progress of disease treatment.

According to previous research, celastrus orbiculatus is a commonly used herb with various biological activities and multiple functions such as activating blood and dissolving stasis, clearing heat and removing toxicity [7]. Moreover, it has been reported that that celastrus orbiculatus has a promising therapeutic efficacy in the treatment of cholecystitis and nephritis [8]. A previous study has stated that Celastrus orbiculatus extract (COE) can effectively inhibit various tumors cells. However, the effect of COE is rarely reported in LC. The $W n t / \beta$-catenin pathway is involved in various physiological processes, and it has been reported to be intimately associated with the progression of tumors [9]. Therefore, this research was designed to assess the influence of COE on the chemosensitivity of LC cells and its mechanism.

\section{EXPERIMENTAL}

\section{Cell line}

Hep G2/ADM cells, a multidrug-resistant cell line of $\mathrm{HCC}$, were purchased from Beina Biotechnology Co. Ltd, a Chinese agent of ATCC.

\section{Cell culture}

The Hep G2/ADM cells were cultivated in RPMI 1640 culture medium with10 \% fetal bovine serum, followed by cultivation in a humid environment with $5 \% \mathrm{CO}_{2}$ at $37{ }^{\circ} \mathrm{C}$, prior to trypsin digestion with a cell density reaching $80 \%$. Subsequently, the cells were portioned into culture flasks at a ratio of $1: 3$ for passaging culture.

\section{Determination of the effect of COE on Hep G2/ADM cells}

Hep G2/ADM cells were digested by trypsin and counted, with the cell concentration adjusted to 1 $\times 10^{5} / \mathrm{mL}$, followed by the inoculation to a 96 -well plate. All cells were distributed to the study group and control group. COE with a concentration of $120 \mu \mathrm{g} / \mathrm{mL}$ was added in the study group, and the culture was continued after treatment. After $48 \mathrm{~h}$, data were collected and analyzed.

\section{MTT assay}

Cells were inoculated to a 96-well plate, with the density of $4 * 103$ cells/well, and cultivation was performed at $37^{\circ} \mathrm{C}$ for $24,48,72$, and $96 \mathrm{~h}$, respectively. At each time point, MTT solution (5 $\mu \mathrm{g} / \mathrm{mL})(20 \mu \mathrm{L})$ was added and cultivated at 37 ${ }^{\circ} \mathrm{C}$ for $4 \mathrm{~h}$, prior to adding $200 \mu \mathrm{L}$ of dimethyl sulfoxide into each well. Then, the OD value in each group was tested via a V-1200 spectrophotometer at $450 \mathrm{~mm}$ wavelength.

\section{Transwell assay}

Cells were collected and inoculated in a 24-well plate, with the density regulated to $3 \times 104$ cells/well, digested by trypsin, and then transferred to the upper chamber. RPMI1640 medium $(200 \mu \mathrm{L})$ was added in the upper compartment, and RPMI1640 (500 mL) (comprising 10\%FBS) was added in the lower compartment. Cultivation of the cells was performed at $37^{\circ} \mathrm{C}$ for $48 \mathrm{~h}$. The cells in the upper compartment were wiped off by using wet cotton swabs, rinsed with PBS, and secured with methanol for $30 \mathrm{~min}$. $0.1 \%$ crystal violet was employed for color development for $20 \mathrm{~min}$, and subsequently rinsed with PBS.

\section{Flow cytometry}

Trypsin digestion $(0.25 \%)$ was performed and the cells were rinsed with PBS twice. The binding buffer $(100 \mu \mathrm{L})$ was added to prepare $1 \times 106$ cells/mL suspension. AnnexinV-FITC and PI were added for culture at room temperature without light for $5 \mathrm{~min}$. FC500MCL flow cytometry instrument was applied for detection.

\section{Western blot analysis}

The study group was divided into group $A$ (containing added $1 \mu \mathrm{mol} / \mathrm{L}$ XAV939) and group 
$B$, and the control group was divided into group C ((containing $1 \mu \mathrm{mol} / \mathrm{L}$ XAV939)) and group D. Proteins were extracted using the RIPA buffer from cultured cells in each group, lysed, and centrifuged at $10000 \times \mathrm{g}$ for $20 \mathrm{~min}$ to obtain the supernatant. Bicinchoninic acid was employed to detect the protein concentration. The proteins of a same amount were segregated for SDS-PAGE, and transferred to a PVDF membrane. 5\% skimmed milk powder was used for blocking at room temperature for $1 \mathrm{~h}$. After electrophoresis, the protein was transferred to PVDF membrane by a membrane transfer instrument. Subsequently, $5 \%$ skim milk was supplemented to block the membrane for $2 \mathrm{~h}$ and rinsed. Then, primary antibodies (1: 1000) were added and sealed for overnight cultivation at $4^{\circ} \mathrm{C}$, and the membrane was rinsed and added with HRPlabeled goat anti-rabbit secondary antibody (1: 5000).

\section{Statistical analysis}

Statistical analysis was performed by using the SPSS 20.0 software, and GraphPad Prism 7 was applied to plot the graphs. The measurement data were represented by (SD \pm means) and were analyzed by t-test. The independentsamples t-test was employed for the comparison between groups, expressed in $t$. One-way ANOVA was used to analyze the comparison among groups. LSD t-test was employed for pairwise comparison. Repeated measures were applied for multi-time point expression. Bonferroni was applied for a post hoc test. $\mathrm{P}<$ 0.05 indicated statistical differences.

\section{RESULTS}

\section{Biological effects of COE on Hep G2/ADM cells}

The study group obtained significantly lower results in terms of multiplication curve and cell invasiveness $(p<0.05)$ and a markedly higher apoptotic rate than the control group $(p<0.05)$. An elevated pro-apoptotic protein Bax level and a reduced anti-apoptotic protein Bcl-2 level was observed in the study group ( $p<0.05$, Figure 1$)$.

\section{Effect of Wnt/ $\beta$-catenin pathway on HEp G2/ADM cells}

The multiplication capacity of Hep G2/ADM cells in group $A$ treated with inhibitor XAV939 was declined $(p<0.05)$. Moreover, the invasiveness capability was also lower than the cells in group $B$ which received no treatment of inhibitor XAV939, while the apoptotic rate in group A was higher than group $B(p<0.05)$. There was an elevation in the pro-apoptotic protein Bax level and a fall in the anti-apoptotic protein Bcl-2 level in group $\mathrm{A}(p<0.05$, Figure 2$)$.
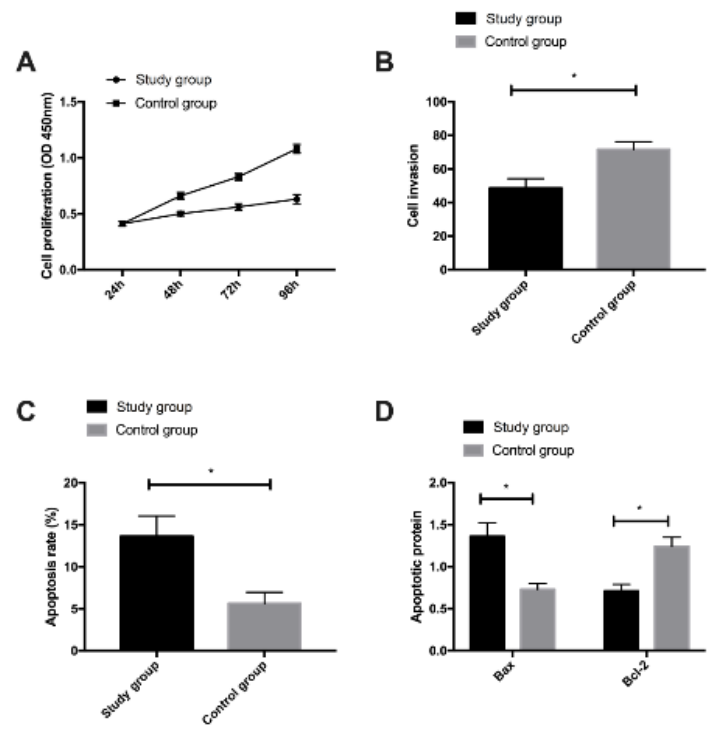

D

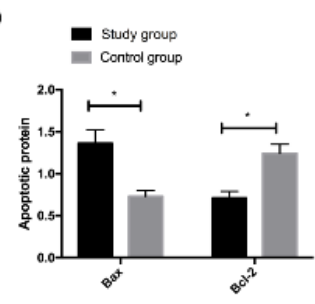

Figure 1: Biological effects of COE on Hep G2/ADM cells. A) Cell proliferation. B) Cell invasion. (C) Apoptosis rate. (D) Apoptosis protein.; ${ }^{*} p<0.05$
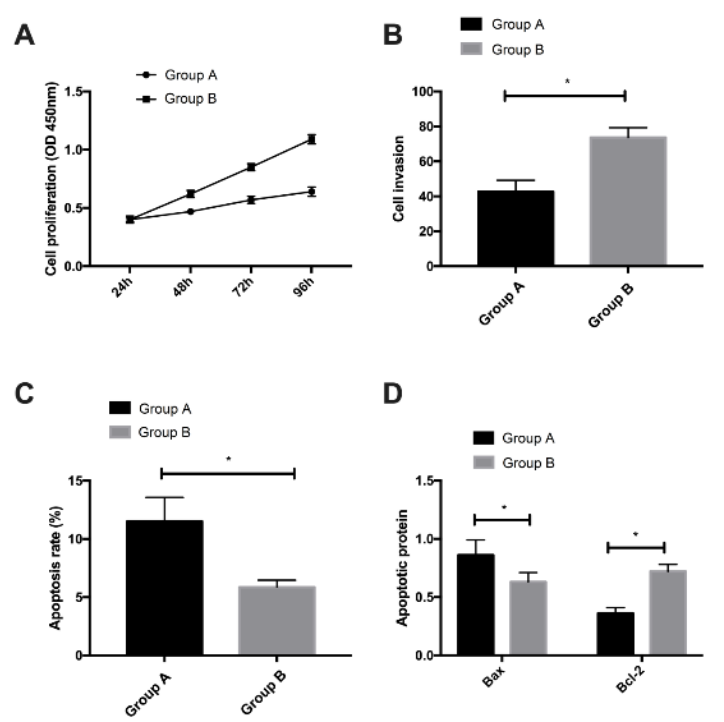

Figure 2: Effect of $W n t / \beta$-catenin pathway on Hep G2/ADM cells. A) Cell proliferation B) Cell invasion. C) Apoptosis. D) Apoptosis protein; ${ }^{*} p<0.05$

\section{Expression of $\beta$-catenin, $c-M y c$, and cyclin D1 protein in RG and CG}

The study group exhibited lower levels of $\beta$ catenin, C-Myc, and cyclin D1 protein expressions than the control group $(p<0.05$, Figure 3). 

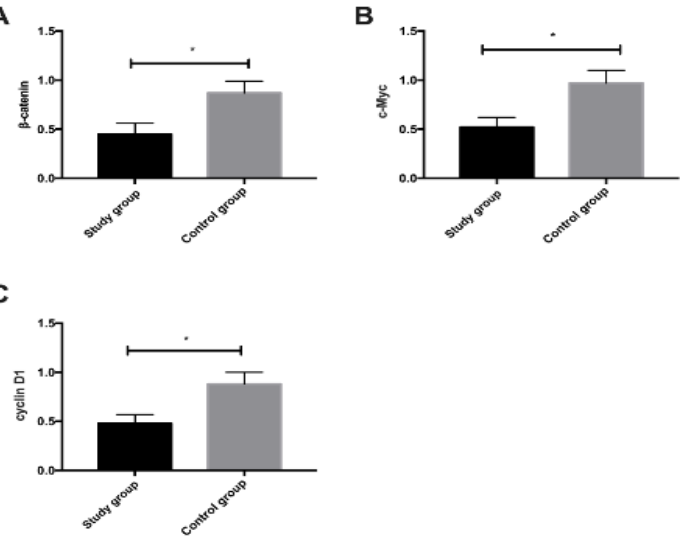

Figure 3: Expression level of $\beta$-catenin, c-Myc, and cyclin D1 protein in the study group and control group. (A) Expression of the $\beta$-catenin protein in the study group and control group. (B) Expression of c-Myc protein in study group and control group. (C) Expression of cyclin D1 protein in study group and control group. ${ }^{\star} P<0.05$

COE affected the chemosensitivity of Hep G2/ADM cells by regulating $W n t / \beta-c a t e n i n$ pathway

The multiplication and invasive capacity of cells in group A treated with COE and inhibitor XAV939 were lower than those in other groups, and the apoptosis rates of the cells in group $A$ were increased $(p<0.05)$. Nevertheless, no great disparity in proliferation, invasiveness, and apoptosis between group B (treated with COE alone) and group $C$ (treated with inhibitor XAV939 alone) was found $(p>0.05)$. The cell multiplication and invasiveness of the cells in groups D without COE and inhibitor XAV939 were increased significantly, while the apoptotic rate was diminished markedly $(p<0.05)$ (Figure 4).

A
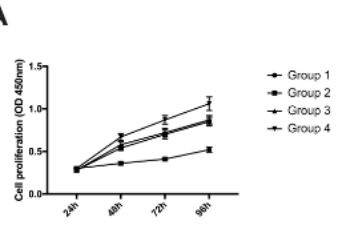

B

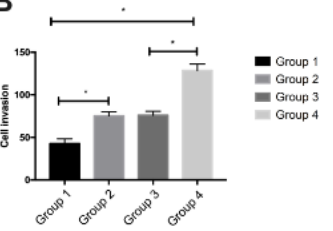

C

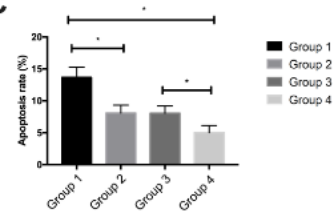

Figure 4: COE affected the chemosensitivity of Hep G2/ADM cells by regulating the Wnt/ $\beta$-catenin pathway. (A) Cell proliferation. (B) Cell invasion. (C) Apoptosis rate; ${ }^{*} p<0.05$

\section{DISCUSSION}

LC is one of the most pervasive malignancies in the alimentary canal, the incidence of which has witnessed an increasing trend in recent years, with rapid disease progression, serious deterioration, and poor five-year survival [10]. Notwithstanding the implementation of comprehensive treatment methods such as surgical resection and chemotherapy in clinical practice, the prognosis of patients still remains much to be desired. Previous research has revealed that malignant tumors are caused by the uncontrolled mechanism of cell growth, proliferation, and apoptosis [11]. For example, the oncogene is activated while the tumor suppressor gene is inactivated, which leads to the continuous metastasis of cancer cells and the growing severity of the disease. The Chinese herbal medicine, Celastrus orbiculatus, is frequently used to dispel wind, promote blood circulation, detoxify and reduce swelling [12]. Herein, the effect and of COE on the chemosensitivity of LC cells and its mechanism were studied.

It was found that the study group had a lower proliferation rate and cell invasiveness than the control group. However, markedly higher apoptosis rate was found in the study group, and study group had an increased pro-apoptotic protein Bax level and a decreased anti-apoptotic protein $\mathrm{Bcl}-2$ level, indicating the anti-cancer role of COE in LC, which is also in line with the findings of a previous study [13], confirming the reliability of our study. It may be attributed to the promising anti-inflammatory and antioxidant effects of COE.

Previous research has revealed that COE can effectively control the activation of NF-kB and mediate the levels of inflammatory factors. Moreover, it can effectively remove oxygen free radicals, inhibit oxidation reactions both inside and outside mitochondria, and increase surface negative charges to avoid damage to the mitochondrial inner membrane [14]. In tumors, COE can significantly reinforce the killing effect on tumor cells through its strong antiviral effect. Although a prior study has pointed out that COE effectively promotes the apoptosis of tumor cells [15], its specific mechanism is still unclear. In was found in this study that the $\mathrm{Wnt} / \beta$-catenin signal pathway exerts an effect on the influence process of COE. The $\mathrm{Wnt} / \beta$-catenin pathway is an important path that regulates pluripotency of stem cells and influences cell differentiation during development [16]. 
It has been confirmed that Wnt/ $\beta$-catenin is highly activated in LC, which stimulates the growth and development of tumor cells [17]. The findings of this research revealed that the activity of Hep G2/ADM declined and the apoptosis rate increased under the intervention of XAV939, which once again confirmed that the suppression of the Wnt/ $\beta$-catenin pathway could reverse the drug resistance of LC cells and accelerate the apoptosis of tumor cells.

The results of the present study also revealed that Wnt/ $\beta$-catenin path-related proteins $\beta$ catenin, c-Myc, and cyclin D1 were declined in Hep G2/ADM under the intervention of COE, which indicated that COE could suppress the expression of $W n t / \beta$-catenin pathway in Hep G2/ADM, preliminarily confirming our above speculation. Then, COE was co-cultured with Wnt / $\beta$ - Catenin path inhibitor. The findings revealed that the activity of Hep G2/ADM cells declined obviously after the co-intervention of COE and XAV939, suggesting that the combination of COE and XAV939 could prominently reinforce the drug resistance of LC cells and the killing effect of chemotherapy drugs on cells. Compared with cells intervened by COE and XAV939, there was no difference in proliferation, invasiveness, and apoptosis, indicating that COE and XAV939 could effectively reverse the drug resistance of LC cells.

The limitations of this study lie in the absence of animal tests and the non-exploration of the optimal dosage for treatment, which may raise some uncertainty regarding the effect of COE on tumors in vivo. However, animal tests and optimal dosage exploration will be conducted in future studies.

\section{CONCLUSION}

COE reverses drug resistance to chemotherapy by inhibiting the expression of $W n t / \beta$-catenin pathway in LC cells, thus indicating its potentials for further development for use along with chemotherapeutic agents in anti-liver cancer therapy.

\section{DECLARATIONS}

\section{Conflict of Interest}

No conflict of interest associated with this work.

\section{Contribution of Authors}

We declare that this work was done by the authors named in this article and all liabilities pertaining to claims relating to the content of this article will be borne by the authors. Xiaobo Ding conceived and designed the study, and drafted the manuscript. Laijun Song and Yunfei Lu collected, analyzed and interpreted the experimental data. Qiting Huang and Chengming Jiao revised the manuscript for important intellectual content. All authors read and approved the final manuscript.

\section{Open Access}

This is an Open Access article that uses a funding model which does not charge readers or their institutions for access and distributed under the terms of the Creative Commons Attribution License (http://creativecommons.org/licenses/by/ 4.0) and the Budapest Open Access Initiative (http://www.budapestopenaccessinitiative.org/rea d), which permit unrestricted use, distribution, and reproduction in any medium, provided the original work is properly credited.

\section{REFERENCES}

1. Anwanwan $D$, Singh SK, Singh $S$, Saikam $V$, Singh $R$. Challenges in liver cancer and possible treatment approaches. Biochim Biophys Acta Rev Cancer 2020; 1873(1): 188314.

2. Soteriades ES, Kim J, Christophi CA, Kales SN. Cancer Incidence and Mortality in Firefighters: A State-of-the-Art Review and Meta-Analysis. Asian Pac J Cancer Prev 2019; 20(11): 3221-3231.

3. Vinceti M, Filippini $T$, Del Giovane $C$, Dennert $G$, Zwahlen $M$, Brinkman M, Zeegers MP, Horneber M, D'Amico R, Crespi CM. Selenium for preventing cancer. Cochrane Database Syst Rev 2018; 1(1): CD005195.

4. Yang Z, Hackshaw A, Feng Q, Fu X, Zhang Y, Mao C, Tang J. Comparison of gefitinib, erlotinib and afatinib in non-small cell lung cancer: A meta-analysis. Int $J$ Cancer 2017; 140(12): 2805-2819.

5. Guo XF, Zhao T, Han JM, Li S, Li D. Vitamin D and liver cancer risk: A meta-analysis of prospective studies. Asia Pac J Clin Nutr 2020; 29(1): 175-182.

6. Li J, Yuan Z, Wang Q, Fan W, Zhang G. Meta-analysis of overall incidence and risk of ALK inhibitors-induced liver toxicities in advanced non-small-cell lung cancer. Medicine (Baltimore) 2019; 98(1): e13726.

7. Shen $Y$, Chen $B L$, Zhang $Q X$, Zheng $Y Z, F u Q$. Traditional uses, secondary metabolites, and pharmacology of Celastrus species - a review. J Ethnopharmacol 2019; 241: 111934.

8. Bai ST, Chen PH, Chen YY, Lin XC, Liu JS, Tong L. Ethyl Acetate Extract from Celastrus aculeatus Merr. Suppresses Synovial Inflammation in Adjuvant Arthritis Rats through Apoptosis Induction of CD4(+)CD25(+)FOXP3(+) T Cells. Evid Based Complement Alternat Med 2014; 2014 : 460136.

Trop J Pharm Res, October 2021; 20(10): 2081 
9. Nguyen VHL, Hough $R$, Bernaudo $S$, Peng C. Wnt/Bcatenin signalling in ovarian cancer: Insights into its hyperactivation and function in tumorigenesis. $J$ Ovarian Res 2019; 12(1): 122.

10. Wang $H$, Lu Z, Zhao $X$. Tumorigenesis, diagnosis, and therapeutic potential of exosomes in liver cancer. $J$ Hematol Oncol 2019; 12(1): 133.

11. Zhang $Q$, Lou $Y$, Bai XL, Liang TB. Immunometabolism: A novel perspective of liver cancer microenvironment and its influence on tumor progression. World $\mathrm{J}$ Gastroenterol 2018; 24(31): 3500-3512.

12. Wansi JD, Wandji J, Sewald N, Nahar L, Martin C, Sarker $S D$. Phytochemistry and pharmacology of the genus Drypetes: A review. J Ethnopharmacol 2016; 190: 328353.

13. Yan X, Qin X, Li W, Liang D, Qiao J, Li Y. Functional characterization and catalytic activity improvement of BAHD acyltransferase from Celastrus angulatus Maxim. Planta 2020; 252(1): 6.
14. Yu H, Venkatesha SH, Moudgil KD. Microarray-based gene expression profiling reveals the mediators and pathways involved in the anti-arthritic activity of Celastrus-derived Celastrol. Int Immunopharmacol 2012; 13(4): 499-506.

15. Venkatesha SH, Dudics S, Astry B, Moudgil KD. Control of autoimmune inflammation by celastrol, a natural triterpenoid. Pathog Dis 2016; 74(6): ftw059.

16. Prossomariti A, Piazzi G, Alquati C, Ricciardiello L. Are Wnt/B-Catenin and PIJK/AKT/mTORC1 Distinct Pathways in Colorectal Cancer? Cell Mol Gastroenterol Hepatol 2020; 10(3): 491-506.

17. Fu $X$, Zhu $X$, Qin F, Zhang Y, Lin J, Ding Y, Yang Z, Shang $Y$, Wang $L$, Zhang $Q$, et al. Linc00210 drives Wnt/B-catenin signaling activation and liver tumor progression through CTNNBIP1-dependent manner. Mol Cancer 2018; 17(1): 73. 